\title{
Outros personagens entraram em cena: o movimento negro e a emergência de uma "política racializada"
}

\section{Other characters entered on the scene: the black movement and the emergence of a "racialized politics"}

\section{Otros personajes entraron en escena: el movimiento negro y la emergencia de una política racializada}

\author{
Hildeberto Vieira Martins* \\ Universidade Federal Fluminense - UFF, Niterói, Rio de Janeiro, Brasil
}

\begin{abstract}
RESUMO
A finalidade desse artigo é discutir a importância do movimento negro a partir da década de 1930 em decorrência do seu papel político no cenário nacional, ao denunciar a existência do preconceito racial no Brasil e a relação desigual entre brancos e negros. Definimos como pontos de referência desse movimento a criação tanto da Frente Negra Brasileira (FNB), em 1931, como do Teatro Experimental do Negro (TEN), em 1944. As duas organizações em suas análises da situação do negro expuseram essa questão frequentemente em termos marcados por conteúdo psicológico, visando explicar ou resolver sua condição de exclusão. Pretende-se discutir o papel desse movimento na difusão de uma discussão sobre a autoimagem do negro e seu papel social a partir da racialização política do lugar desse sujeito histórico no Brasil.
\end{abstract}

Palavras-chave: questão racial, racismo, movimento negro, identidade racial, história da psicologia.

\begin{abstract}
The present article to discuss the importance of the black movement from the 1930s on account of its political role on the national scene when denouncing the existence of racial prejudice in Brazil and the unequal relationship between whites and blacks. We defined as reference points of this movement the creation of both the Frente Negra Brasileira (FNB) in 1931 and the Teatro Experimental do Negro (TEN) in 1944. The two organizations in their analysis of the situation of the Negro often presented this question in terms marked by a psychological content whose attempt was to explain or solve their condition of exclusion. What we want to discuss is the role of this movement in the diffusion of a discussion about the black self-image and its social role from the political racialization of the place of this historical subject in Brazil.
\end{abstract}

Keywords: racial issue, racism, black movement, racial identity, history of psychology. 


\begin{abstract}
RESUMEN
La finalidad de este artículo es discutir la importancia del movimiento negro a partir de la década de 1930 como consecuencia de su papel político en el escenario nacional al denunciar la existencia del prejuicio racial en Brasil y la relación desigual entre blancos y negros. En 1931 se definió como puntos de referencia de ese movimiento la creación tanto del Frente Negra Brasileira (FNB), en 1931, como del Teatro Experimental do Negro (TEN), en 1944. Las dos organizaciones, en sus análisis de la situación del negro, expusieron esta cuestión frecuentemente en términos marcados por un contenido psicológico, cuyo intento era explicar o resolver su condición de exclusión. Lo que se pretende discutir es el papel de ese movimiento en la difusión de una discusión sobre la autoimagen del negro y su identidad a partir de la racialización política del lugar de ese sujeto histórico en Brasil.
\end{abstract}

Palabras clave: cuestión racial, racismo, movimiento negro, identidad racial, historia de la psicología.

\title{
I ntrodução
}

O título do nosso trabalho é uma referência direta ao já clássico livro de Eder Sader, "Quando novos personagens entraram em cena: experiências, falas e lutas dos trabalhadores da Grande São Paulo, 1970-1980", texto que discute o papel e a importância dos movimentos sociais, mais especificamente o movimento dos trabalhadores do ABC paulista, e o impacto desses movimentos na "criação de um novo sujeito social e histórico" (Sader, 1988). Contudo, como fica evidente no próprio subtítulo do livro citado, o objetivo de Sader naquele momento era discutir o contexto histórico e político de uma classe específica (os trabalhadores), de um lugar específico (a Grande São Paulo), em um momento específico (19701980). E assim como Sader, alguns autores trataram a década de 1970 como um momento fundamental para a emergência desses novos movimentos sociais, o que fez com que essa fase ganhasse de Ruth Cardoso a alcunha de "emergência heroica dos movimentos" (Cardoso, 1994, p. 81).

As razões que levaram Sader a fazer tais escolhas ficam bem evidentes em seu memorável trabalho e nos serviram de base para refletir sobre outro período histórico da sociedade brasileira e a partir disso realizar o estudo e a análise de um grupo de sujeitos políticos. Essa reflexão é fruto da nossa discordância em relação à tese principal do trabalho de Sader, pois o que pretendemos com esse texto é demonstrar que já entravam em cena "novos atores" na década de 1930, rótulo cabível àqueles que a partir do protagonismo capitaneado pelo movimento negro organizaram, inicialmente em São Paulo, novas formas de luta em prol do reconhecimento de direitos sociais e políticos constitutivos de um modelo republicano para o negro. Se seguirmos as premissas sugeridas por Marilena Chauí no prefácio do livro de Eder Sader a respeito da "criação de um novo 
sujeito social e histórico" (Sader, 1988, p. 10), e acompanharmos as ações sociais do movimento negro intitulado Frente Negra Brasileira (FNB), não podemos deixar de constatar que no início da década de 1930 os mesmos fundamentos que corroboraram essa premissa teórica de Chauí já estavam presentes. O próprio Eder Sader, ao final do capítulo I, comentando a emergência desses "novos atores sociais", caracteriza esse "sujeito coletivo" como "uma coletividade onde se elabora uma identidade e se organizam práticas através das quais seus membros pretendem defender seus interesses e expressar suas vontades, constituindo-se nessas lutas" (Sader, 1988, p. 55). Mais adiante reitera seu caráter coletivo ao afirmar que esse novo sujeito histórico é na verdade

“[...] uma pluralidade de sujeitos, cujas identidades são resultado de suas interações em processos de reconhecimento recíproco, e cujas composições são mutáveis e intercambiáveis. As posições dos diferentes sujeitos são desiguais e hierarquizáveis; porém essa ordenação não é anterior aos acontecimentos, mas resultados deles." (Sader, 1988, p. 55).

Essa breve digressão teve o intuito de apresentar as questões que norteiam esse artigo. O que propomos como tema de discussão é um esboço preliminar de uma investigação que toma como objeto de análise os usos dos saberes psicológicos (psicologia, psicanálise e psiquiatria) e sua constituição como modelo científico utilizado para definir os limites de cidadania para aqueles que eram considerados "perigosos" à ordem social (Martins, 2009), e que aqui segue a seguinte coordenada: a emergência de um ativismo político negro pós-abolição, que se consolidou na década de 1930, capitaneado pelos "homens de cor" (como era referida a população considerada negra no início do século $X X$ ), e que nesse trabalho se estenderá até os anos 1950, momento em que o conceito de negritude, usado como estratégia subjetiva de construção de uma identidade étnico-racial, começa a ser uma ferramenta política do movimento negro, que repensava o seu papel nos debates sobre a questão racial no Brasil, como bem demonstrado por Elisa Larkin Nascimento (Nascimento, 2003).

Com isso, não queremos afirmar que não existia um protagonismo negro antes desse período, o que já ficou bem demonstrado em alguns trabalhos, como os de Gomes (2005), Lima (2003) e Chalhoub (1990). O que seguimos como linha argumentativa principal é que a década de 1930 vê emergir o primeiro movimento negro organizado de caráter nacional, personificado na figura da Frente Negra Brasileira (FNB) e logo em seguida a sua consolidação, representada pelo surgimento do Teatro Experimental do Negro (TEN). Os marcos desse novo horizonte político se situam a partir da emergência de dois 
eventos significativos: primeiro, o surgimento da FNB, entidade fundada em 16 de setembro de 1931 (por Arlindo Veiga dos Santos, Justiniano Costa, I saltino Veiga dos Santos, José Correia Leite, entre outros), na cidade de São Paulo, e que teve papel destacado nos debates raciais surgidos nos primeiros anos da década de 1930; o segundo acontecimento foi a criação do TEN, em 1944 por um grupo de militantes negros (Abdias Nascimento, Ruth de Souza, Alberto Guerreiro Ramos, Sebastião Rodrigues Alves, entre outros).

Nesse mesmo período também ocorreram alguns congressos dedicados à discussão da questão racial no Brasil e que tiveram um enorme impacto na vida intelectual e cotidiana brasileira. São eles: o I Congresso Afro-Brasileiro de 1934, em Recife; o II Congresso AfroBrasileiro de 1937, ocorrido em Salvador; e o I Congresso do Negro Brasileiro, realizado em 1950, no Rio de Janeiro. Outros eventos ocorreram ao longo desse período histórico, mas somente os citados anteriormente serão objeto de uma breve análise nesse trabalho, dada a relevância que tiveram sobre a discussão racial da época.

Portanto, o que queremos debater é como em grandes centros populacionais (mais especificamente, Rio de Janeiro e São Paulo) um novo personagem político (o ativismo negro), circunscrito em um determinado período (1930-1950), pôde construir as condições possíveis para a rediscussão do problema racial brasileiro, e com isso suscitar uma redefinição dos papéis sociais vigentes para esse "elemento negro", muito em decorrência da proliferação de uma "imprensa negra" que coloca em debate ideias sobre o "problema negro" diante do silêncio que o tema provoca. Isso gerou tensões sociais que fomentaram a efetivação de uma "política racializada", ou seja, tensões que favoreceram (e ainda favorecem) a emergência de um debate político que tomou a questão racial como um problema crucial para entender a manutenção das desigualdades na sociedade brasileira.

O que trazemos aqui para a nossa discussão é o quanto o ativismo negro compreendido entre as décadas de 1930-1950 fez parte dos enfrentamentos sociais contra determinadas pautas conservadoras vigentes durante esse período republicano. Para Petrônio Domingues esse ativismo produziu uma "nova Abolição", expressão que foi cunhada pelo jornal Clarim da Alvorada, um dos jornais publicados no período definido por certa historiografia como o da eclosão de uma "imprensa negra" (Domingues, 2008; Ferrara, 1985; Bastide, 1983). O projeto de uma "nova Abolição" tinha como objetivo principal realizar "uma transformação radical capaz de assegurar a igualdade de direitos e oportunidades para negros e brancos na sociedade brasileira" (Domingues, 2008, p. 170-171). Para muitos autores, esse novo ativismo político foi consolidado a partir da criação da FNB, considerada a maior organização afro-brasileira de grande impacto 
nacional, surgida nas primeiras décadas da era republicana (Domingues, 2011, p. 162; Hanchard, 2001, p. 48).

Definimos esses atores sociais como agentes insurgentes (ou "revoltados"), ou seja, como representantes de movimentos minoritários (raciais e sociais) que buscam produzir as ferramentas necessárias para colocar em xeque um determinado funcionamento social excludente. E não parece ser sem motivo que Abdias Nascimento tenha publicado em 1968 um livro intitulado "O negro revoltado", livro iniciado em 1950 e que reúne os Anais do I Congresso do Negro Brasileiro (Nascimento, 1982). Veremos como esse ativismo político foi também um projeto de construção de uma autoimagem e identidade racial em um momento em que a imagem do negro era fundamentalmente vinculada a características morais, psicológicas e sociais negativas (Cf. Martins, 2009). Pensamos o movimento negro dessa época como um movimento "trânsfuga" da ordem social instituída, ou seja, como promotor autônomo de formas de resistência à lógica racial hegemônica (pensamos o conceito de transfugir como aquilo que caracteriza um movimento ativo de abandono ou ruptura com as causas ou compromissos sociais e políticos que anteriormente eram defendidos ou aceitos como norma). Esses atores sociais procuraram questionar o funcionamento social vigente na tentativa de promover a abertura de um novo caminho para o problema racial brasileiro, e por isso eles podem ser vistos como profetizadores de um "novo negro", já que ao criarem um novo campo de debate sobre o tema racial, invertem a lógica social vigente e impõem a reconfiguração dessa arena política, o que obrigava o Estado, a sociedade civil e a academia a pensar que "democracia racial" estava sendo aventada e louvada no Brasil. Contudo, não podemos ignorar que esse mesmo movimento negro reproduziu certos vícios e naturalizações presentes no discurso hegemônico da época sobre o negro, ao que nos parece, por uma apropriação inicialmente acrítica de conceitos e noções científicas que vigoravam naqueles anos.

O que aqui está sendo nomeado de "ativismo negro pós-Abolição" é esse processo de constituição inicial de uma ruptura histórica com o que até então vigorava com o nome de "democracia racial", e o termo é tomado de empréstimo da literatura histórica e sociológica sobre os movimentos negros produzidos nas últimas décadas. Os movimentos negros inauguraram uma ruptura conjuntural na década de 1930 e provocaram um debate até então mascarado pelo simulacro social brasileiro presente na noção de "democracia racial". Essa nova arena de debate e de embate produzida por uma política racializada, ou seja, pela racialização das relações sociais, culminará com a participação cada vez mais ativa do movimento negro. Para finalizar este ponto, não podemos deixar de apontar outra característica comum às duas organizações. Tanto a FNB como o TEN 
expõem em seus veículos de divulgação ("A Voz da Raça" e o "Quilombo", respectivamente) certas análises da situação social do negro marcadas por um conteúdo de cunho psicológico. Consideramos tal postura como uma tentativa de explicar e encontrar alternativas possíveis que tirassem o negro da sua condição de exclusão. Um exemplo dessas análises pode ser verificado na transcrição de um trecho do jornal A Voz da Raça, intitulado "Proclamação aos inspetores, subinspetores e fiscais e cabos", e escrito por Mario da Silva Junior:

Meus irmãos negros! Tudo quanto se tiver fora de nossas tradições e dos nossos regulamentos deve ser repelido, mas tudo que estiver dentro dos regulamentos e das nossas tradições, deve ser acatado e cumprido. A psicologia frentenegrina tem seus mistérios, mas um chefe experimentado, num rápido golpe de vista, poderá sempre ler o que vai no fundo d'alma e deduzir... É o que esta chefia procurou fazer, dirigi-me ao coração dos cabos, perscrutar-lhes os sentimentos. (Silva Junior, 1933, p. 3, grifo nosso)

Configurado o quadro de análise que propomos realizar, passemos para a exposição de uma narrativa que sustente os nossos argumentos.

\section{Novos atores para um novo Brasil: a emergência do movimento negro}

Precisamos iniciar o debate sobre a emergência do movimento negro propondo uma definição do que aqui estamos chamando de movimento negro. Utilizamos como referência os trabalhos de Petrônio Domingues, que em um dos seus artigos comenta ser esse "um tema subexplorado na historiografia brasileira", afirmando ainda que se deve tomar o conceito de raça como "fator determinante de organização dos negros em torno de um projeto comum de ação", ou seja, como estratégia política de uma parcela da sociedade brasileira (Domingues, 2007, p. 101). A escolha dos seus trabalhos segue algumas premissas metodológicas que acreditamos justificar seu uso, pois o autor: é reconhecidamente um pesquisador da história do movimento negro (Domingues, 2018, 2011, 2008, 2007). O escopo cronológico de suas análises históricas sobre o movimento negro (entre 1889-2000) permite uma visão mais abrangente de suas mudanças; seus trabalhos influenciaram outras pesquisas sobre essa questão (Passos \& Nogueira, 2014; Gomes, 2012); a caracterização feita por Domingues do movimento negro vai ao encontro de nossa concepção de que esse movimento já apresenta as principais 
características inerentes à ideia de um "novo sujeito social e histórico", como pensado somente na década de 1970 por Eder Sader. Por isso nós nos valemos da análise que Domingues faz do movimento negro como um "movimento político de mobilização racial (negra)" (Domingues, 2007, p. 101-102).

Consideramos que discutir o movimento a partir desse princípio permite uma delimitação analítica que possibilita um maior entendimento do que queremos debater nesse texto. Um segundo aspecto referente às opções metodológicas desse artigo diz respeito ao uso da pesquisa documental e bibliográfica como recurso investigativo. O uso de documentos é um critério metodológico bastante difundido no campo científico, e não só no âmbito das ciências humanas e sociais. Tratando-se de pesquisa sobre movimentos sociais, essa é uma ótima forma de compreender a trajetória, a dinâmica interna e o que tais coletividades queriam transmitir para a sociedade como sendo suas aspirações e objetivos. A pesquisa documental do jornal A Voz da Raça foi feita a partir do sítio da Biblioteca Nacional (http://bndigital.bn.gov.br/hemerotecadigital/). Outros materiais de pesquisa foram obtidos através de pesquisa bibliográfica, seja por meio de fontes primárias, seja pelo uso de fontes secundárias de estudo. É nesse sentido que a utilização do material publicado pela FNB e o TEN é um instrumento útil para entender as pretensões que tais organizações tiveram à época de seu funcionamento, complementada por uma bibliografia sobre essas organizações. Por isso optamos por reproduzir trechos de alguns documentos formulados pelos movimentos negros compreendidos no período desse estudo. Para ilustrar, iniciamos nossa exposição com um trecho do Estatuto da FNB:

Artigo I - Fica fundada nesta cidade de São Paulo, para se irradiar por todo o Brasil, a 'FRENTE NEGRA BRASILEIRA', união política e social da Gente Negra do Brasil, para afirmação dos direitos históricos da mesma, em virtude da sua atividade material e moral no passado e para reinvindicação dos seus direitos sociais e políticos, atuais, na comunhão brasileira.

Artigo II - Podem pertencer à Frente Negra Brasileira todos os membros da Gente Negra Brasileira de ambos os sexos, uma vez capazes, segundo a lei básica nacional.

Artigo III A 'FRENTE NEGRA BRASILEIRA', como força social, visa a elevação moral, intelectual, artística, técnico-profissional e física: assistência e proteção e defesa social, jurídica, econômica e do trabalho da Gente Negra.

Parágrafo único - Para a execução do Artigo III, criará cooperativas econômicas, escolas técnicas e de ciências e artes e campos de esporte dentro de uma finalidade rigorosamente 
brasileira. (Domingues, 2008, pp. 61-62; Barbosa, 1998, p. 110, grifo nosso)

Nesse primeiro momento de organização político-social, o que o movimento negro desejava era a ampliação nacional de um debate que buscasse evidenciar "a afirmação dos direitos históricos" da população negra, ou seja, se desejava o funcionamento de várias frentes políticas que fizessem valer a garantia "dos seus direitos sociais e políticos", que até àquele momento não eram uma realidade em nossa sociedade. Esses sujeitos acreditavam que essa mudança social só poderia ser viável se houvesse uma ação cooperativa voltada para a "elevação moral, intelectual, artística, técnicoprofissional e física" do elemento negro em nossa sociedade, elevação que deveria ser capitaneada e promovida por essa entidade, já que o Estado brasileiro não havia realizado ainda a integração desse elemento ao corpo social nacional e não demonstrava interesse em dar andamento a tal projeto. Esse projeto de integração do negro concorria com o efetivo movimento estatal de valorização da imigração europeia e do mal disfarçado desejo de branqueamento de parcela da sociedade brasileira. Não escapou a esses atores sociais compreender o delicado debate político eclodido na Europa nas décadas de 1920-1930, e que provocou graves conflitos sociais, marcados por forte conotação racial. O fascismo, que se espalhava por todo o mundo ocidental, e a consequente discussão do posicionamento da sociedade brasileira diante desse quadro geopolítico, ficou retratado em artigos publicados no jornal A Voz da Raça, periódico publicado pela FNB (Domingues, 2008, p. 68). Contudo, não podemos deixar de comentar, que se Arlindo Veiga dos Santos, presidente da FNB de 1931 a 1934, e alguns outros membros da FNB mantinham fortes laços com o integralismo e simpatia com os regimes autoritários (Domingues, 2008, p. 68-79), afirmar categoricamente que o nível de penetração do integralismo nesse movimento era realmente majoritário é um equívoco, pois o forte viés nacionalista que a FNB tinha por característica principal era bastante comum à época (Gomes, 2005, p. 53).

Fundada em São Paulo no dia 16 de setembro, localizada na Rua da Liberdade, no 196, a FNB tinha como lema “Deus, Pátria, Raça e Família", principio que vinha estampado também em seu jornal A Voz da Raça (Domingues, 2008, p. 61; Gomes, 2005, p. 49). Foi com o intuito de ampliar e difundir as ideias dessa entidade que esse periódico foi criado em 1933, contando com a publicação de 70 edições, cujo propósito era abordar as inquietações, os interesses e os preconceitos de cor sofridos pela população negra. A partir do seu lema "Deus, Pátria, Raça e Família", é possível perceber o caráter um tanto quanto conservador e nacionalista que marca a linha editorial do jornal. Um aspecto enfatizado por esse jornal era o notório 
favorecimento que existia na sociedade brasileira em relação aos estrangeiros brancos e amarelos, e seus filhos, frente aos brasileirosnatos e de cor. A crescente constatação de uma maior ascensão social desses estrangeiros a partir do processo de industrialização paulista, provoca uma maior rejeição à figura do estrangeiro (xenofobia), o que se verifica em textos do jornal, como no trecho abaixo, publicado em 13 de maio de 1933, escrito por Isaltino Veiga dos Santos:

Outros dizem que a ação da F.N.B. pode trazer para o Brasil uma QUESTÃO que não existe, com tendência a uma divisão racial, mas nada disso existe, não adianta esse envenenamento, não é nada disso que se prega na Frente Negra Brasileira, o que desejamos é sempre estar ao lado dos nossos irmãos brancos, em todos os ramos de atividade, especialmente na parte em que toca a nossa nacionalidade... ainda mesmo que aqueles, por qualquer motivo fujam de nossa convivência, nós os frentenegrinos os procuramos, por que só compreendemos um Brasil forte e unido, com a união de todos os brasileiros, sem distinção de cor ou credo político, mesmo porque, se nós os negros estamos afastados da vida política da nacionalidade, a culpa cabe tão somente a falada aristocracia brasileira, que se envergonhando da sua própria descendência, nos jogou a margem de todas as atividades, dando concessões escandalosas aos estrangeiros, substituindo até na lavoura, os negros pelos mesmos. E foi por essa e outras coisas idênticas que se fundou a Frente Negra Brasileira, mesmo porque o negro já está cansado de ouvir dizer que ele não serve pra nada, está cansado de tanto ludibrio e de tanta diminuição; assim sendo de cabeça altiva, a raça quase unida pleiteia e pleiteará dentro da ordem os seus direitos como brasileiros que são e que nunca deixaram de ser, já tendo dado para isso sobejas provas, especialmente nas horas em que a pátria periga. A nossa luta, visa, está visto, a nossa completa emancipação social e política... (Santos, 1933, p.1, grifo nosso)

A diretoria da FNB era composta majoritariamente por intelectuais negros, e tinha como objetivo principal a integração do negro na vida do país e o seu aprimoramento moral e social. Para realizar tal intento, essa entidade promoveu pioneiramente cursos de alfabetização de adultos e crianças, oferecia consultas médicas, aulas de música e ainda contava com um setor jurídico responsável pela defesa dos direitos dos negros frentenegrinos. Ao mesmo tempo que essa entidade surge com o intuito de defender o negro e suas origens étnicas (como a valorização da luta de Palmares), ela reproduzia certos estereótipos racistas, como a ideia que o negro era o elemento 
não civilizado e atrasado da sociedade brasileira, que devia abandonar certos comportamentos negativos (vadiagem, alcoolismo), procurando adotar os valores morais que de maneira naturalizante eram creditados ao padrão de vida do branco. Adotando tal postura, o negro inevitavelmente garantiria as condições ideais para a sua entrada no "mundo dos brancos" e a efetivação de uma verdadeira "democracia racial". Seguir certo padrão (moral) de conduta era o caminho viável para que isso acontecesse, e por isso não beber tanto, alisar o cabelo, seguir a doutrina cristã e estar devidamente trajado seriam exemplos da aceitação e inserção nesse processo civilizatório, calcado nos moldes de um padrão social esperado e desejável (burguês e branco).

A preocupação com um estilo de vida apropriado fica evidente pelo uso frequente nos jornais do movimento negro da época da noção de "classe de cor", e que funcionava como um contraponto à noção de "preto comum" (Gomes, 2005, p. 36 e segs.). O papel das atitudes e comportamentos da comunidade negra era um tema usualmente abordado no jornal. E curiosamente Cesare Lombroso (1835-1909) serviu para corroborar as críticas comportamentais formuladas por alguns representantes da FNB, como pode ser constado nessa análise de Castelo Alves sobre o conceito de tara sexual:

Taras se diz de uma certa tendência espiritual ou psíquica que arrasta 0 individuo para a pratica de atos e costumes formalmente reprovados pela moral, e os tarados quando não tem a devida educação para se conter, tornam-se insuportáveis e perigosos para a sociedade. A tara é, pois, um estado de alma hereditário. O filho de um ébrio ou bêbado, não só manifesta muito cedo a inclinação para o vicio, como também são possuidores de outras propensões que acompanhara porventura os pais viciosos, como seja - libidinagem, homicídio, meretrício, falta de caráter etc. sendo que neste ponto falam bem alto todos os cientistas, principalmente os médicos psiquiatras que descobrem na tara o principal fator da alienação mental e nós cremos certa essa afirmativa da ciência porque temos notado nas crianças filhas de ébrios grande falta de capacidade para aprenderem a leitura e toda e qualquer disciplina fácil para outras cujos pais tenham-se conservado sóbrios ou mais ou menos puros. [...] A tara está com todas as raças e no seio de todos os povos como um entorpecente das melhores qualidades. Seria mais fácil evitar o tarado que curála visto que o único medicamento eficaz é a educação sistemática nas escolas, como já o afirmara Lombroso em sua Medicina Legal. Evitaríamos a tara combatendo o alcoolismo e a sífilis como fatores principais, evitando-se o alcoólatra e o sifilítico, e estes por sua vez, num lampejo de bom senso evitar 
constituir proles de infelizes como até hoje. Como o negro deseja reerguer-se, é bom que se saiba como evitar a tara para a nossa felicidade e grandeza da pátria. Para bem se entender meia palavra basta... (Alves, 1933, p. 1, grifo nosso)

Outro aspecto bastante abordado nas colunas do jornal diz respeito ao problema da desunião dentro da própria FNB, fator que atrapalhava o movimento negro em seu objetivo de alcançar a integração à sociedade brasileira. Para a FNB, o negro que não tinha coesão, fé, amor à sua nação, que esperava regalias do movimento, que não procurava continuar a luta, era também um inimigo dessa causa. Na leitura das páginas do jornal fica evidente qual era o papel da "gente negra": ter caráter, disciplina, ser capaz de sacrificar-se em prol do coletivo, - afinal, se o próprio negro se apresentava como inimigo do movimento a luta pela liberdade de nada valia. Isso fica evidente no texto de Isaltino Veiga dos Santos, intitulada "Aos negros de boa vontade":

[...] ou o negro brasileiro se define de uma vez por todas como gente séria, de caráter, nobre, morigerada, capaz de sacrifícios pela coletividade, capaz de compreender as grandes causas que sacodem a Pátria Brasileira e a humanidade toda, - ou deve ser varrido e aniquilado como gente perniciosa, incapaz de compreensão, incapaz de se premunir contra exploradores imorais, contra pescadores de aguas turvas, contra os inimigos do próprio Negro e da Nacionalidade (Santos, 1933, p. 4, grifo nosso).

As passagens acima ilustram ideias contundentes a respeito do lugar e do papel do negro em nossa sociedade. Vozes que às vezes só reproduzem imagens estereotipadas que circulavam sobre o negro, mas que viam isso como única saída para o seu acesso ao "mundo dos brancos". Esperava-se com isso a ascensão de um "novo negro", porque mais "sério, de caráter e nobre". A descrição de algumas passagens do jornal A Voz da Raça serve para elaborar um quadro preliminar de como tal veículo midiático funcionou como um importante mecanismo de difusão das ideias e anseios de parcela desse grupo social, assim permitindo estratégias de inserção no seio de uma sociedade preconceituosa.

\section{Os Congressos Afro-brasileiros}

Outros espaços de debate sobre as ideias e os sentimentos que nortearam as discussões e esperanças sobre a população negra da época foram os Congressos Afro-Brasileiros, realizados em 1934 e 
1937. O I Congresso Afro-Brasileiro ocorreu em Recife, em 1934, e foi organizado por Gilberto Freyre (1900-1987) e Ulisses Pernambucano (1892-1943) e tinham como objetivo principal apresentar trabalhos que discutissem a contribuição da população negra para o Brasil. Por essa razão o Congresso contou com a participação de um número variado de estudiosos da cultura afrobrasileira como antropólogos, ialorixás, babalorixás, negros de engenho, vendedoras baianas, rainhas de maracatu, estudantes de direito, de engenharia e medicina, velhos folcloristas etc.(Freyre, 1937, p. 348-349). Seu principal homenageado foi Raimundo Nina Rodrigues (1862-1906), que mais tarde seria considerado um dos precursores do racismo científico no Brasil. Nas palavras de Gilberto Freyre, esse Congresso "[...] foi o menos solene dos congressos. Nele não brilhou um colarinho duro. Não apareceu um fraque. Não trovejou um tribuno. Não houve um só discurso em voz tremida. Foi tudo simples em voz de conversa." (Freyre, 1937, p. 348). O evento contou com a apresentação de trabalhos variados, como do pesquisador Melville Herskovits, famoso antropólogo americano, e de um representante da Frente Negra Pelotense, Miguel Barros. Cabe destacar um trecho da sua exposição nesse congresso:

A Frente Negra Pelotense, entidade que tem por lema: União, Cultura e I gualdade, que devem ser invocadas, quando se inicia um movimento, portentoso e inédito do elevamento moral, intelectual e social do negro; de uma raça entregue à si mesma e que não tem outra coisa senão sua extraordinária capacidade de trabalho e inteligência virgem, que deve e merece ser cultivada. Para que essa massa, que foi na submissão, sempre dirigida, sem a menor noção de humanidade; impedida de sair do marasmo, da inatividade; embargada nos passos para uma arrancada sublime e patriótica, que viria fortalecer, de uma vez por todas, uma terra, que se pouco fez, foi somente porque essa grande maioria de $80 \%$ da população brasileira, vive à parte, no analfabetismo e que necessita de uma segunda abolição, que desenvolva a mente, para que se interesse pelos problemas, que the dizem respeito, que a levará ao caminho extraordinário que conduz a evolução humana. (Barros, 1935, p. 269, grifo nosso)

A fala de Miguel Barros reafirma alguns pontos capitais da luta promovida pela FNB desde 1931, o que só confirma a coesão e coerência interna presente nesse movimento, seja daqueles que participavam em São Paulo, seja de seus participantes do Rio Grande do Sul.

O que Gilberto Freyre desejava com a realização desse congresso era enfatizar 0 espírito de igualdade pretendido por aqueles que 
participavam do evento. Mas como ficou evidente nas décadas seguintes, o que o sociólogo corroborava era a ideia de uma suposta "democracia racial" no Brasil. Segundo ele, o congresso "deu novo feitio e novo sabor aos estudos afro-brasileiros" já que contou com a colaboração de "analfabetos, de cozinheiras, de pais de terreiro, ao lado dos doutores" (Freyre, 1937, p. 351). Afirmada a mudança mais "democrática" e de cunho culturalista, os estudos afro-brasileiros se reconfiguravam.

Como parte dos resultados advindos do impacto social desses novos "estudos afro-brasileiros" um livro foi publicado um ano depois contendo parte dos trabalhos apresentados nesse congresso - contou com o prefácio do médico e antropólogo Edgard Roquette Pinto (1884-1954) -, tendo como título Estudos Afro-Brasileiros (Freyre, 1935); um segundo livro seria lançado em 1937 com os trabalhos restantes, intitulado Novos Estudos Afro-Brasileiros (Freyre, 1937). Esse último livro contou com o prefácio do médico psiquiatra Arthur Ramos, um estudioso da presença do negro no Brasil e autodeclarado discípulo de Nina Rodrigues.

Já o II Congresso ocorreu na Bahia, de 11 a 19 de janeiro 1937, e teve como principal organizador Edison Carneiro, um dos principais estudiosos da cultura africana e afro-brasileira da época. Realizado no Instituto Geográfico e Histórico da Bahia, o evento deu grande ênfase ao contexto cultural e as contribuições da tradição de matriz africana. Raimundo Nina Rodrigues foi novamente homenageado pelo papel que teve como pioneiro nesse campo de estudos. O congresso contou novamente com a participação ativa de representantes do candomblé, inclusive na apresentação de trabalhos. Décadas depois, esses dois congressos seriam denunciados por parte do movimento negro como eventos que falavam sobre o negro ("objeto") e não voltados para os negros ("protagonista").

O que tentamos afirmar até agora é que enquanto a FNB discutia a situação concreta pela qual passava o negro na sociedade brasileira (dificuldade de acesso aos direitos sociais básicos e a experiência cotidiana do "preconceito de cor"), os dois congressos ocorridos no mesmo período tentavam discutir qual era a contribuição étnico-racial e cultural do negro para a sociedade brasileira, uma forma de abordagem do "problema negro" que depois será rotulada pelo movimento como "acadêmica". A FNB, extinta em 1937 no bojo da instauração da ditatura orquestrada por Getúlio Vargas (Estado Novo), buscava construir planos de ação que revertessem a condição de subalternidade na qual se encontrava a população negra através de cursos de alfabetização (cursos primário e de alfabetização de adultos), da organização de eventos esportivos, sociais e culturais (Barbosa, 1998, p. 18-20). Com o fim da FNB, houve uma tentativa de dar continuidade aos seus projetos por parte de alguns de seus participantes, que a rebatizaram de União Negra Brasileira 
(Domingues, 2008, p. 68). A duração desta, contudo, foi muito breve, abrindo um hiato político que mais tarde foi preenchido pelo surgimento do Teatro Experimental do Negro (TEN), em 1944.

\section{O TEN como um experimento das "aspirações do negro"}

A década de 1940 foi palco do surgimento do Teatro Experimental do Negro (TEN), movimento fundado no Rio de Janeiro, e que segundo um de seus fundadores, Abdias Nascimento:

[...] se propunha a resgatar, no Brasil, os valores da pessoa humana e da cultura negro-africana, degradados e negados por uma sociedade dominante que, desde os tempos da colônia, portava a bagagem mental de sua formação metropolitana europeia, imbuída de conceitos pseudo-científicos sobre a inferioridade da raça negra. Propunha-se o TEN a trabalhar pela valorização social do negro no Brasil, através da educação, da cultura e da arte. (Nascimento, 2004, p. 210, grifo nosso)

E mais adiante aponta que a atuação do movimento ocorreu a partir de duas linhas de frente: “(...) promover de um lado, a denúncia dos equívocos e da alienação dos chamados estudos afro-brasileiros, e fazer com que o próprio negro tomasse consciência da situação objetiva em que se achava inserido" (Nascimento, 2004, p. 211, grifo nosso). Encontramos no TEN a repetição da compreensão da situação do negro em nossa sociedade quase uma década depois, ao percebermos que essa organização se valeu basicamente das mesmas estratégias que já haviam sido encaminhadas pela FNB:

A um só tempo o TEN alfabetizava seus primeiros participantes, recrutados entre os operários, empregados domésticos, favelados sem profissão definida, modestos funcionários públicos - e oferecia-Ihes uma nova atitude, um critério próprio que os habilitava também a ver, enxergar o espaço que ocupava o grupo afro-brasileiro no contexto nacional. Inauguramos a fase prática, oposta ao sentido acadêmico e descritivo dos referidos e equivocados estudos [sobre o negro]. Não interessava ao TEN aumentar o número de monografias e outros escritos, nem deduzir teorias, mas a transformação qualitativa da interação social entre brancos e negros. (Nascimento, 2004, p. 211, grifo nosso)

Contudo, se nós nos detivermos no trecho extraído da apresentação de abertura do I Congresso do Negro Brasileiro, realizado no Rio de 
Janeiro, em 1950, pelo TEN verificamos que o tom era mais de continuidade que de equívoco entre "práticos" e "acadêmicos":

Este I Congresso do Negro Brasileiro, promovido pelo Teatro Experimental do Negro, e que ora inauguramos em nome da comissão organizadora, abre uma nova fase nos estudos dos problemas das relações de raça no Brasil. [...] Porque os brasileiros de cor, patrioticamente interessados no estudo dos meios que os conduzam à sua integração definitiva na nacionalidade, através da ascensão social e econômica possibilitada pela educação e pela cultura, estão praticamente liderando a elaboração de um pensamento, precipitando e forçando a cristalização de uma política racial cujo conteúdo ideológico se encontra em nossa tradição, em nossos costumes, que nunca permitiram ou endossaram a supremacia de um grupo étnico sobre os representantes de outras raças. Observamos que a larga miscigenação praticada como imperativo de nossa formação histórica, desde o início da colonização do Brasil, está se transformando, por inspiração e imposição das últimas conquistas da biologia, da antropologia e da sociologia, numa bem delineada doutrina de democracia racial, a servir de lição e modelo para outros povos de formação étnica complexa, conforme é o nosso caso. [...] Sem qualquer mácula de ressentimento, os brasileiros de cor tomam a iniciativa de reabrir os estudos, as pesquisas e as discussões levantadas por vários intelectuais, principalmente pelos promotores do I e II Congressos Afro-Brasileiros do Recife e da Bahia, respectivamente, já agora não apenas com a preocupação estritamente científica, porém aliando à face acadêmica do conclave o senso dinâmico e normativo que conduz a resultados práticos. (Nascimento, 1982, p. 121-122, grifo nosso)

Podemos ver nesses trechos uma série de questões que permeavam e ainda permeiam o debate racial brasileiro e que se tornam evidentes na forma de definir o papel dos congressos e a abordagem que deveria nortear os debates sobre a questão racial. As falas acima, pronunciadas por Abdias Nascimento, uma ocorrida em 26 de agosto de 1950 e a outra somente em 2004, congregam questões já esboçadas pela FNB na década de 1930, mas trazem novos pontos de vista. Se antes havia a consolidação de um "credo racial" à brasileira, cristalizado na ideia repetida pelo TEN de uma "doutrina de democracia racial", e que nesse momento serve de sinal indicativo da nossa singularidade enquanto nação, nas décadas posteriores essa crença seria colocada em cheque e repudiada por esse mesmo movimento negro. A rediscussão do "problema negro", anteriormente 
iniciada pelos estudos acadêmicos apresentados nos I e II Congressos Afro-Brasileiros do Recife e da Bahia, seria redefinida por uma visão que adquire uma conotação que privilegia uma postura mais "prática" do papel do movimento negro e que com isso anunciava as divergências e os novos caminhos que esses atores pretendiam inaugurar, ou seja, a investida em um novo modelo de discussão ocasionado pela imposição ("precipitada" e "forçada") de uma política social racializada.

Assim como a FNB, o TEN fundamentava-se na ideia que para mudar o lugar social dos negros era necessário haver uma maior ênfase nos aspectos educacionais e a criação de bases econômicas mais sólidas para que uma nova classe social negra surgisse. É com esse propósito que o TEN investiu na produção artística e cultural de seus participantes e em sua alfabetização, usando como estratégia a montagem de peças teatrais, reunindo em suas aulas operários, funcionários públicos, empregadas domésticas, que depois de alguns meses de aula promovidas por alguns de seus idealizadores poderiam atuar nas peças encenadas pelo TEN.

Abdias Nascimento entendia que havia questões sociais e políticas que impediam o processo de libertação da população negra da sua condição subalterna. Na revista Quilombo em um artigo intitulado "Espírito e Fisionomia do Teatro Experimental do Negro", afirma:

Reconhecemos no início de nosso empreendimento a necessidade de apelar para uma tática sociológica, ou seja, para um tipo de ação não idealista e tampouco ideológica, mas sensível e ajustada à configuração psico-social, cuja transformação almejávamos. Com efeito, se estudarmos a vida das associações de homens de cor neste país, colheremos a lição de que a maioria delas tem fracassado precisamente por carecerem daquilo que poderemos chamar de atitude sociológica. [...] O Teatro Experimental do Negro pertence à ordem dos meios [de ação.]. Ele é um campo de polarização psicológica, onde se está formando o núcleo de um movimento social de vastas proporções. A massa dos homens de cor, de nível cultural e educacional normalmente baixo, jamais se organizou por efeito de programas abstratos. A gente negra sempre se organizou objetivamente, entretanto, sob o efeito de apelos religiosos ou interesses recreativos. Os terreiros e as escolas de samba são instituições negras de grande vitalidade e de raízes profundas, dir-se-ia, em virtude de sua teluricidade. O que devemos colher desta verificação é que só poderemos reunir em massa o povo de cor mediante a manipulação das sobrevivências paideumáticas subsistentes na sociedade brasileira e que se prendem às matrizes culturais africanas. A mentalidade da nossa população de cor é ainda pré-letrada e 
pré-logica. As técnicas sociais letradas ou lógicas, os conceitos, as ideias mal a atingem (sic). [...] Tal é a fisionomia do T.E.N. A Conferência Nacional do Negro se integra nesse programa como instrumento de decifração do negro brasileiro. Com efeito, a população de cor, em virtude de seu baixo nível cultural, não tem a preparação necessária para definir seus próprios problemas (sic). Precisamos ouvir os estudiosos, consultar os entendidos e ouvir os próprios negros (Nascimento, 2003, p. 45).

Como fica bastante evidente nesse trecho, o uso de uma linguagem psicológica para descrever a condição do negro era empregada "como instrumento de decifração do negro brasileiro". Na revista Quilombo também era comum o uso de noções científicas (como o conceito de mentalidade pré-lógica, de Lucien Lévy-Bruhl) que corroborassem uma explicação do suposto "baixo nível cultural" dessa população. Se levarmos em consideração que tais comentários partiram de um grande ativista negro brasileiro, talvez o maior de nosso país, podemos ter uma pequena ideia de como certas apropriações do discurso científico da época, hoje considerados falsos e ultrapassados, produziam seus efeitos concretos (e deletérios) na sociedade como um todo. Anos mais tarde Abdias rejeitaria tais ideias.

Destacamos ainda outro exemplo que revela como esses modelos científicos e psicológicos faziam parte das estratégias construídas pelo movimento negro em sua tentativa de transformar a realidade cotidiana dessa população, e que ficou representada pelos trabalhos conduzidos por Alberto Guerreiro Ramos juntos aos participantes do TEN a partir do que ele definiu como "Seminário de Grupoterapia" (Domingues, 2008, p. 72). Há uma primeira exposição desse procedimento no jornal Quilombo, de julho de 1949, quando Guerreiro Ramos comenta sobre a Conferência Nacional do Negro, organizada pelo TEN:

Com efeito quem se der ao trabalho de ler o discurso com o qual o Sr. Abdias Nascimento, instalou aquele conclave [Conferência Nacional do Negro] verificará que o conhecido líder descobriu uma pista jamais suspeitada entre nós, ou seja, e de pelo teatro adestrar os homens de cor nos estilos de comportamento de classe média e superior. Retoma, assim, este negro a significação original do teatro como processo catártico, numa poderosa intuição artística e sociológica. [...] Não estamos, pois, diante de mais um explorador da ignorância das populações de cor. Definindo o Teatro Experimental do Negro, como um 'experimento psico-sociológico' o seu criador faz lembrar o famoso Grupo de Oxford com os seus intentos de 
renascença religiosa e o grupo francês de L'Ordre Nouveau, inspirado pelo saudoso filósofo Arnaud Dardieu (sic) e também orientado para a reconstrução social através da pessoa humana. [...] A técnica social do T.E.N. pode ser chamada de grupoterapia. Ela encontra similar na técnica do psicodrama e do sociodrama de J. L. Moreno que dirige dois teatros psicoterapêuticos em Beacon Hill e em New York. O T. E. N., não é orientado truculenta e agressivamente contra o preconceito de cor. Ao contrário, proclama pela palavra de seu criador, não ser essa a tática acertada de ser usada em 'nossa' questão racial, tão diferente da norte-americana. Ele é um campo de polarização psicológica, onde o homem encontra oportunidade de eliminar suas tensões e seus recalques. [...] Todas as assembleias da Conferência nada mais foram que experiências grupoterápicas. (Ramos, 2003, p. 53, grifo nosso)

Esse assunto foi retomado no jornal em janeiro de 1950 quando da divulgação do Seminário de grupoterapia ministrado por Guerreiro Ramos.

O 'Instituto Nacional do Negro', que é o departamento de pesquisadas e estudos do Teatro Experimental do Negro, inaugurou no dia 19 de janeiro, no 3 andar da A. B. I. dependência do Serviço nacional de Teatro - o seu novo órgão, - Seminário de Grupoterapia. Presente uma assembleia constituída de elementos do T.E. N., estudiosos dos problemas da gente de cor, intelectuais e escritores, proferiu a aula inaugural o professor Guerreiro Ramos, sociólogo de renome e diretor do I. N. N. Dado o grande interesse despertado e a importância de que se reveste a experiência desse Seminário que vai apresentar pela primeira vez no Brasil representações de psico-dramas e sócio-dramas, publicamos abaixo o resumo da aula inaugural do professor Guerreiro Ramos. (Apresentação da Grupoterapia, 2003, p. 64, grifo nosso)

Como descrito no trecho acima, essa deve ter sido a primeira exposição dos conceitos e da técnica de psicodrama e sociodrama no Brasil, e coube a Guerreiro Ramos tal feito. A proposta do TEN era, portanto, substituir as antigas formas de responder ao "preconceito de cor" ("truculenta e agressivamente") por uma estratégia mais "psicológica". Fica demonstrado o quanto tais ideias e práticas de inspiração psicológica estavam presentes na rotina do movimento negro da época. O pioneirismo da divulgação de tais técnicas só acentua o nível de penetração dos saberes psicológicos no movimento e na sociedade brasileira. 


\section{Considerações finais}

Traçar, mesmo que brevemente, a trajetória de dois movimentos políticos que tiveram como temática principal a situação do negro no Brasil, cujo objetivo era transformar a sua condição social de subalternidade e desigualdade econômico-social, contribui, ao nosso ver, significativamente para a compreensão do Brasil e de suas desigualdades e para montar um quadro mais nítido da nossa atual situação. Retratar alguns aspectos das questões que nortearam os objetivos e anseios da Frente Negra Brasileira (FNB) e o Teatro Experimental do Negro (TEN) serve para demonstrar como ainda estamos distantes de um projeto político e social igualitário no Brasil. A pesquisa realizada a partir de uma análise preliminar dos materiais que documentaram os anseios e necessidades de uma parcela da população negra (os jornais A Voz da Raça e Quilombo), nos permitiram vislumbrar o campo de embates em torno da questão racial que se configurava nas primeiras décadas no Brasil (19301950).

O que apresentamos aqui é um esboço preliminar de um campo ainda pouco explorado na história da psicologia, e que esperamos ensejar debate sobre o papel social e político do movimento negro e das formas como tais movimentos se apropriaram e foram influenciados por determinados conceitos e noções de cunho científico. O debate sobre as formas de recepção científica e as trajetórias de sua vulgarização ocorridos no Brasil merece um debate cada vez maior. A expectativa é que as questões levantadas aqui possam favorecer o surgimento de novas pesquisas que produzam desdobramentos ainda não pensados sobre a importância desse movimento na construção de uma identidade social racializada no Brasil e sobre a emergência de um protagonismo político capaz de transformar uma realidade desigual engendrada em nossa sociedade.

\section{Referências}

Apresentação da Grupoterapia. (2003). In A. Nascimento (Org.), Quilombo: vida, problemas e aspirações do negro (pp. 64). Edição fac-similar do jornal dirigido por Abdias Nascimento. São Paulo: Fundação de Apoio a Universidade de São Paulo/Editora 34.

Alves, C. (1933, Novembro 11). "Os tarados". A Voz da Raça, 1(25), 1. Recuperado de http: //memoria.bn.br/DocReader/DocReader.aspx?bib $=845027$ $\&$ PagFis $=33 \&$ Pesq $=0$ \% 20 tarados 
Barbosa, M. (Org.). (1998). Frente Negra Brasileira: depoimentos/entrevistas e textos: Márcio Barbosa. São Paulo: Quilombhoje.

Barros, M. (1935). Discurso do representante da Frente Negra Pelotense. In Congresso Afro-Brasileiro Recife, B., Freyre, G. (1935-37). Estudos Afro-brasileiros: trabalhos apresentados ao 10 Congresso Afro-Brasileiro reunido no Recife em 1934 (pp. 269-271). Rio de Janeiro: Ariel.

Bastide, R. (1983). A imprensa negra no Estado de São Paulo. In R. Bastide, Estudos Afro-brasileiros (pp. 129-156). São Paulo: Perspectiva.

Cardoso, R. C. L. (1994). A trajetória dos movimentos sociais. In Cardoso, R. \& Dagnino, E. (Orgs.), Os anos 90: política e sociedade no Brasil (pp. 81-90). São Paulo: Brasiliense.

Chalhoub, S. (1990). Visões da liberdade: uma história das últimas décadas da escravidão na corte. São Paulo: Companhia das Letras.

Domingues, P. (2018). "Tudo pelo Brasil; tudo pela raça": a Frente Negra Carioca. Revista Estudos Históricos, 31(65), 327-348. doi: 10.1590/s2178-14942018000300002

Domingues, P. (2011). "O caminho da verdadeira emancipação": a Federação dos Negros do Brasil. In F. Gomes \& P. Domingues (Org.), Experiências da emancipação: biografias, instituições e movimentos sociais no pós-abolição (1890-1980) (pp. 157184). São Paulo: Selo Negro, 2011.

Domingues, P. (2008). A nova abolição. São Paulo: Selo Negro.

Domingues, P. (2007). Movimento negro brasileiro: alguns apontamentos históricos. Tempo, 12(23), 100-122. doi: 10.1590/S1413-77042007000200007

Ferrara, M. (1985). A imprensa negra paulista (1915/1963). Revista Brasileira de História, 5(10), 197-207.

Freyre, G. (Org.). (1937). Novos Estudos Afro-Brasileiros: trabalhos apresentados ao 1을 Congresso Afro-Brasileiro do Recife (Vol. 2). Rio de Janeiro: Editora Civilização Brasileira.

Freyre, G. (1935). Estudos Afro-Brasileiros: trabalhos apresentados ao 10 Congresso Afro-Brasileiro reunido no Recife em 1934. Rio de Janeiro: Ariel.

Gomes, F. (2005). Negros e política (1888-1937). Rio de Janeiro: Zahar.

Gomes, N. L. (2012). Movimento negro e educação: ressignificando e politizando a raça. Educação \& Sociedade, 33(120), 727-744. doi: 10.1590/S0101-73302012000300005

Hanchard, M. G. (2001). Orfeu e poder: o movimento negro no Rio de Janeiro e São Paulo (1945-1988). Rio de Janeiro: EdUERJ .

Lima, I. S. (2003). Cores, marcas e falas: sentidos da mestiçagem no Império do Brasil. Rio de Janeiro: Arquivo Nacional. 
Martins, H. V. (2009). As ilusões da cor: sobre raça e assujeitamento no Brasil (Tese de Doutorado). Instituto de Psicologia, Universidade de São Paulo, São Paulo, SP.

Nascimento, A. (2004). Teatro experimental do negro: trajetória e reflexões. Estudos Avançados, 18(50), p.209-224. doi: 10.1590/S0103-40142004000100019

Nascimento, A. (2003). Espírito e Fisionomia do Teatro Experimental do Negro. In A. Nascimento (Org.), Quilombo: vida, problemas e aspirações do negro (pp. 45). Edição fac-similar do jornal dirigido por Abdias Nascimento]. São Paulo, FAUSP/Editora 34.

Nascimento, A. (1982). O negro revoltado (2a ed.). Rio de Janeiro: Nova Fronteira.

Nascimento, E. L. (2003). O sortilégio da cor: identidade, raça e gênero no Brasil. São Paulo: Selo Negro.

Passos, J. C., \& J. C. Nogueira (2014). Movimento negro, ação política e as transformações sociais no Brasil contemporâneo. Política \& Sociedade, 13(28), 105-124. doi:10.5007/21757984.2014v13n28p105

Ramos, A. G. (2003). Uma experiência de grupoterapia. In A. Nascimento (Org.), Quilombo: vida, problemas e aspirações do negro (pp. 53). Edição fac-similar do jornal dirigido por Abdias Nascimento. São Paulo, Fundação de Apoio a Universidade de São Paulo/Editora 34.

Sader, E. (1988). Quando novos personagens entraram em cena: experiências, falas e lutas dos trabalhadores da Grande São Paulo, 1970-1980. Rio de Janeiro: Paz e Terra.

Santos, I. V. dos. (1933, Maio 13). Liberdade Utópica. Voz da Raça, 1(9), $1 . \quad$ Recuperado de http://memoria.bn.br/DocReader/DocReader.aspx?bib=845027 \&PagFis=36\&Pesq $=$ ut\% C3\% B3pica

Silva Junior, M. (1933, Março 18). Proclamação aos inspetores, subinspetores e fiscais e cabos. A Voz da Raça, 1(1), 3. Recuperado http://memoria.bn.br/DocReader/DocReader.aspx?bib $=845027$ \&PagFis $=33 \&$ Pesq $=u t \%$ C3\%

\section{Endereço para correspondência \\ Hildeberto Vieira Martins}

Universidade Federal Fluminense - UFF

Departamento de Psicologia de Rio das Ostras - RPS

Rua Recife, s/n, Jd. Bela Vista, CEP 28.890-000, Rio das Ostras - RJ, Brasil

Endereço eletrônico: hvmartins@id.uff.br

Recebido em: 19/12/2018

Reformulado em: 02/03/2019

Aceito em: 04/03/2019 


\section{Notas}

* Psicólogo, bacharel e licenciado em Psicologia pela Universidade do Estado do Rio de Janeiro (UERJ), mestre em Saúde Coletiva pelo Instituto de Medicina Social da UERJ (IMS-UERJ) e doutor em Psicologia Social pelo Instituto de Psicologia da Universidade de São Paulo (IPUSP). Professor associado da Universidade Federal Fluminense (UFF), pesquisando os temas relações raciais no Brasil, história da psicologia, psicologia social e produção de subjetividade.

Financiamento: FAPERJ .

Este artigo de revista Estudos e Pesquisas em Psicologia é licenciado sob uma Licença Creative Commons Atribuição-Não Comercial 3.0 Não Adaptada. 